\title{
A Cross-country Investigation of Perceived Stress During COVID-19 Pandemic: The Impact of Situational Factors and Personality Traits
}

Ngoc Minh Do ( $\sim$ ngocdm@hanu.edu.vn )

Research

Keywords: public health, perceived stress, situational factors, personality traits, cross-country comparison

Posted Date: August 3rd, 2020

DOI: https://doi.org/10.21203/rs.3.rs-51277/v1

License: (c) (i) This work is licensed under a Creative Commons Attribution 4.0 International License.

Read Full License 


\section{Abstract}

The study investigates the public mental health cross-national during the global COVID-19 pandemic. Analysis of data collected from people across different countries shows that people are experiencing moderate stress level and demonstrates that stress level is affected by internal genetic factor and external conditions. Specifically, perceived stress is affected by personality traits and contextual settings namely residence location, personal finance situation, and usage of social media during the pandemic.

\section{Introduction}

In the end of 2019, beginning of 2020, the Coronavirus COVID - 19 took the world for a storm as it quickly spread out to most nations within only a few months, and was declared a global pandemic, with nearly 8 millions infected and nearly half a million dead (and counting) (worldometers, 2020). Many nations declared quarantine order, cancel large gatherings, and even close off borders in an attempt to slow the virus spread. Starting as a health crisis, it rapidly escalated to creating negative social, economic and political impact. People's lives are disrupted when schools are closed, adults work at home, businesses recorded huge losses and even bankruptcy, many lose their jobs and are left hungry and homeless. With such challenging conditions, it is predictable that people would experience emotional distress, especially when many nations place a compulsory social distancing and quarantine that bounds people at home. This study aims to investigate mental health during the Covid- 19 by examining stress levels of people in relation to external factors (contextual settings) and genetic factors (personality traits).

\section{Literature Review}

Lazarus (1990) viewed stress response as the result of the interaction between humans and environment, which means that individuals would differ in their perception of stress. In the transactional model of stress developed by Lazarus and Folkman (1984), individuals experience two appraisal processes, one to evaluate the external stressors and personal stake and the other evaluates personal resources to cope with stressors; stress occurs when imbalance between stressors' demands and personal resources to cope with such demands. When judging a situation to perceive threats, individuals differ in terms of perception and cognitive appraisal, which leads to varied interpretation of situations. People differ in terms of personal resources to cope with external threats, which means how they react to perceived threat is not the same as well.

Even though personality was not specifically included in the transactional model of stress, it clearly impacts individuals' cognitive appraisal processes. Trait theory views personality traits as patterns of thoughts and action, and there are characteristics that are stable and consistent across situations (Costa and McCrae, 1992). However, there are studies that proved personality traits can fluctuate and be changed and even in a short time frame (see for example, Wilson et al., 2016; Wrzus and Roberts, 2017; Sherman et al., 2015). Whatever the case it is, the relationship between perceived stress and personality has been widely accepted as previous research has proved the relationship between personality and 
subjective perception of stress. Vollrath (2001) believed that personality affect the descriptive representation of situation and evaluative perception of situation. Cross-sectional and longitudinal studies showed a significant association between personality and perceived stress (Ebstrup et al., 2011).Shields et al. (2016) discovered that change in perceived stress is strongly related to change in pessimism on a weekly basis. Kondratyuk and Morosanova (2014) found out that high level of neuroticism and introversion can lead to high chronic stress. Şahinn and Çetin (2017) conducted a weekly assessment study and confirmed that neuroticism and extraversion predict perceived stress. The cross-sectional population-based research by Feizi et al. (2014) proved that people with high neuroticism tend to have high level of stress and anxiety, and those with high extraversion and consciousness have lower the chance of high psychological stress. Borkoles et al. (2018) linked Type D personality to increased level of perceived stress and discovered that people with Type D personality tend to search the environment for threats.

As defined, stress response is the interaction of environment and individuals, debate on the role of environmental factors and personal factors on perceived has attracted attention. The study by Luo et al., (2017) found that genetic factors largely explained for the concurrent relation and the continuity between the two; meanwhile, environmental factors played a more significant role in the association between changes in personality and in perceived stress. Similarly, the research on students by Schmidt et al. (2013) showed that structural conditions explained perceived stress better than personality. Lebois et al. (2016) proposed that situations of certain features (such as containing self-threat, negative affect, certainty elements, etc.) can predict the level of stress that people perceive. For example, the work by Onah (2003) about pregnant Nigerian women's perception of environmental stressors confirmed that economic, futuristic, health and social factors caused increase in stress. Or the research by Kallio et al. (2020) found that people can be more stressed out by the poor quality of the environment. Knight et al. (2013) demonstrated that contract-related factors (such as having contracts or not, working hours) influence stress level of coaches in Canada. Similarly, the examination on team work by Guznov et al. (2010) found an association between high neuroticism and higher stress and workload for individuals in the position of having direct control but not in other positions, which suggests the effect of external environmental demands (social interactions required in a team role).

To provide a comprehensive picture, this study proposes that perceived stress is influenced by personality traits and context but does not attempt to identify nor compare the magnitudes of such impacts.

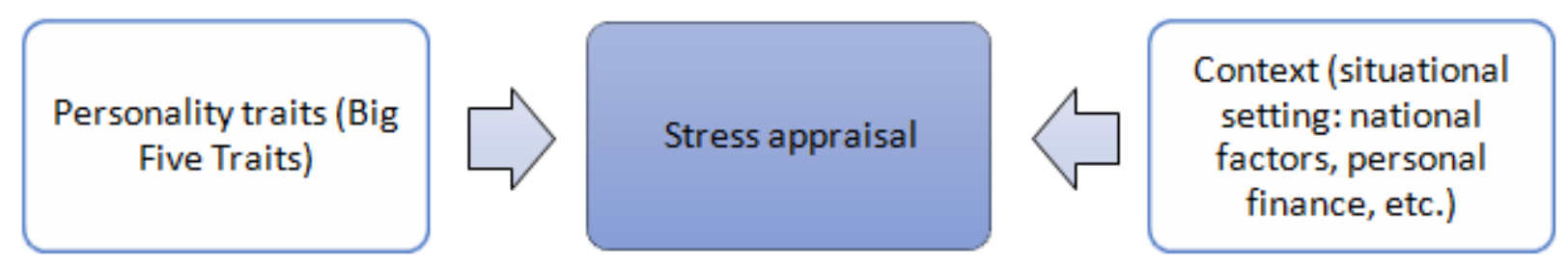




\section{Methodology}

\section{Procedure}

A survey questionnaire was administered and distributed online on randomly selected Facebook groups that have members living in Vietnam and foreign countries. The questionnaire was open for three weeks, from mid April to the beginning of May, when the virus started to spread uncontrollably, the number of infected cases skyrocketed worldwide, chaos and system overload happened, many countries $\mathrm{h}$ declared national lock-downs. After three weeks, a total of 219 responses were collected on Google Form, 3 were not valid, leaving only 216 eligible responses. The survey comprises three sections: the first one asks about personal information and personal circumstances during Covid-19 pandemic, the second section and the third section measure personality and perceived stress scale respectively.

\section{Instruments}

Personality is measured on five domains, using a 30-item short form questionnaire tested and refined by Soto and John (2017). The questionnaire is developed based on the Big Five Model, one of the most popular frameworks (McCrae and Costa, 1999); many have praised the model in examining stable personality traits in threatening situations (see Besser and Shackelford, 2007; Hojat et al., 2003). The Big Five Model examined five personality traits: Extroversion, Agreeableness, Neuroticism, Conscientiousness, and Openmindedness. In this study, the term "Neuroticism" is replaced by the term "Negative Emotionality" to be consistent with the original questionnaire by Soto and John. The level (high or low) of each trait is calculated by adding up the scores of the questions that measure the trait.

To measure stress, the Perceived Stress Scale (PSS) developed by Sheldon Cohen and his colleagues (1983) was used. It is one of the most popular psychological instruments used to measure individuals' perceived stress. The PSS is a self-reported scale that asks about individuals' experience of perceived stress in the last 30 days. Among the three versions of the scale: PSS-14, PSS-10, and PSS-4, the 10-item version was selected to use in this study. There are 10 questions in the scale, each asks the interviewee to chose the option that best describes their frequency of experiencing the stressful situations. The original scale was 0 - Never, 1 - Almost Never, 2 - Sometimes, 3 - Fairly Often, 4 - Very Often. The scale used in this study kept the same 5 levels of frequency, but changes the numbering of each option as followed: 1 - Never, 2 - Almost Never, 3 - Sometimes, 4 - Fairly Often, 5 - Very Often. Score for each question is added up to calculate the level of perceived stress; scores ranging from 0-13 is considered as low stress, $14-26$ is considered as moderate stress, $27-40$ is considered as high stress.

\section{Data}

The research sample consisted of 216 people living in 21 countries affected by Covid -19 pandemic. Specifically, $44 \%$ of the respondents are living in Vietnam, 39\% are living in European countries, and the rest are residing in other nations (see Table 1 ). Around $90 \%$ of the respondents are living in quarantined areas (see Table 2), more than $80 \%$ of them believe that quarantine helps to prevent the spread of the 
virus. $60 \%$ of the respondents are female (131 people), around $39 \%$ are male ( 85 people), and only $1 \%$ identified themselves as others (2 people). Nearly half of the participants (48\%) are from age 25 to 34 , $29 \%$ are from age 35 to 49 , around $10 \%$ are from 18 to 24 and over 50 , only a minority are under 18 . In terms of employment status, half of the respondents are full-time employed, $6 \%$ are part-time employed, $17 \%$ are self-employed, $19 \%$ are students (including those on scholarship), and the rest are other types of employment (such as housewives, unemployed, etc.).

\section{Table 1. Population of respondents by Residing country}

\begin{tabular}{|llllll|}
\hline \multicolumn{1}{|c|}{ Residing_country } & & & & \\
\hline \multirow{2}{*}{ Valid } & & Frequency & Percent & Valid Percent & Cumulative Percent \\
\cline { 2 - 6 } & Vietnam & 95 & 44.0 & 44.0 & 44.0 \\
\cline { 2 - 6 } & Europe & 87 & 40.3 & 40.3 & 84.3 \\
\hline Others & 34 & 15.7 & 15.7 & 100.0 \\
\hline Total & 216 & 100.0 & 100.0 & \\
\hline
\end{tabular}

Table 2. Population of respondents by Quarantined area

\begin{tabular}{|c|c|c|c|c|c|}
\hline \multicolumn{6}{|c|}{ Living_in_quarantined_area } \\
\hline & & Frequency & Percent & Valid Percent & Cumulative Percent \\
\hline \multirow[t]{4}{*}{ Valid } & Yes & 194 & 89.8 & 89.8 & 89.8 \\
\hline & No & 20 & 9.3 & 9.3 & 99.1 \\
\hline & Others & 2 & .9 & .9 & 100.0 \\
\hline & Total & 216 & 100.0 & 100.0 & \\
\hline
\end{tabular}

\section{Results}

\section{Perceived stress level and Personality}

The relationship between personality and perceived stress are determined by Pearson Correlation. The results showed a relationship between personality and perceived stress level.

To be more specific, with $r=0.417, p<0.01$, Negative Emotionality was proved to have a positive moderate relationship with perceived stress level. This could be understood as the higher level of negative emotionality is, the higher the stress level is. 
With $r=-0.184, p=0.007<0.01$, it can be concluded that there is a weak negative relationship between Conscientiousness and perceived stress level, which means the lower level of conscientiousness a person has, the higher level of stress he/she perceives.

The ANOVA test was run to investigate whether different groups recorded different personality. With Sig. = $0.001<0.05$ and Sig. $=0.043<5$, the result showed that different age groups vary in Negative Emotionality and Conscientiousness respectively. There are no differences in personality by Gender and Nationality.

Then, means of the groups were compared to further investigate the differences in personality.

The result shows that the older people are, the lower level of negative emotionality they experience, and that people in the age group from 35 to 49 have the highest level of conscientiousness.

\section{Stress level during Covid-19 period}

Data were collected using a random sampling method from 216 participants across different countries. The result showed that the majority of respondents perceived moderate level of stress during the Covid19 period $(M=20.75, S . D=5.243)$

Then, ANOVA test was run to examine whether different groups report different stress level.

The result: Sig. $=0.037<0.05$ proves that there is a difference in stress level among people who have different usage of social media during the quarantine period.

Similarly, with Sig $=0.031<0.05$, it means that people having personal finance affected by the Covid-19 pandemic experienced different stress levels.

And Sig $=0.018<0.05$ shows a difference in stress level of people living in different countries.

Then, means of groups are compared to look more specifically into the differences in stress levels. Table 11 shows that people living in Vietnam experienced less stress than those from Europe.

\section{Table 3. Perceived Stress in different destinations}




\begin{tabular}{|llll|}
\hline Report & & & \\
\hline Perceived.Stress & & & \\
\hline Residing_country & Mean & $\mathrm{N}$ & Std. Deviation \\
\hline Vietnam & 20.1684 & 95 & 5.41993 \\
\hline Europe & 21.9310 & 87 & 4.90323 \\
\hline Others & 19.3529 & 34 & 5.11019 \\
\hline Total & 20.7500 & 216 & 5.24316 \\
\hline
\end{tabular}

Not surprisingly, the result in Table 4 demonstrates that people whose finance is negatively affected by the pandemic experienced higher stress compared to those whose finance is stable.

Table 4. Perceived Stress of people having finance affected

\begin{tabular}{|llll|}
\hline Report & & & \\
\hline Perceived.Stress & & & \\
\hline Personal_finance_affected & Mean & N & Std. Deviation \\
\hline Finance affected & 21.4113 & 124 & 4.97639 \\
\hline Not affected & 19.8587 & 92 & 5.48441 \\
\hline Total & 20.7500 & 216 & 5.24316 \\
\hline
\end{tabular}

Interestingly, based on Table 5, it seems that the more hours that people spend on social media, the higher level of stress they experience.

Table 5. Perceived Stress by the level of social media usage

\begin{tabular}{|llll|}
\hline Report & & & \\
\hline Perceived.Stress & & & \\
\hline Daily_usage_of_social_media & Mean & N & Std. Deviation \\
\hline Less than 2 hours & 18.8600 & 50 & 5.15479 \\
\hline 2 - 4 hours & 20.7778 & 99 & 5.12209 \\
\hline Over 5 hours & 22.1194 & 67 & 5.12428 \\
\hline Total & 20.7500 & 216 & 5.24316 \\
\hline
\end{tabular}

\section{Discussion}


This study is the first one to examine people's stress in different countries during Covid-19. The research aims to investigate the relationship between stress level and personality and how contexts may affect people's stress.

The first finding confirmed the relationship between personality traits and perceived stress level. Analysis of data showed that perceived stress is positively related to negative emotionality (or neuroticism), and negatively related to conscientiousness. This result of negative emotionality and perceived stress is in line with previous research by many authors, such as the ones by Fornés-Vives, et al. (2012), Dalia, Lucia and Nathalie (2017), or Conard and Matthews (2008). Individuals with high scores of negative emotionality have more difficulties in controlling emotion and are more likely to experience negative emotions; therefore, it is logical that they tend to have higher level of stress than those that have low negative emotionality. On the other hands, trait of conscientiousness is found to have a negative relationship with perceived stress, which means that the more conscientious a person is, the lower level of stress he perceives. This outcome concurs with existing literature, such as the study by Luo and Roberts (2015) who stated that people who increased in conscientiousness experienced less stress over time. Because conscientiousness is related to positive thinking and positive reappraisals (Watson and Hubbard, 1996), it is comprehensible that high level of conscientiousness is associated with low level of stress. Even though the result of data agrees with existing research on the impact of genetic factor (personality traits) on perceived stress, the validity of this finding may be questioned and calls for further investigation due to the small sample size.

The second finding of the paper illustrated the impact of situational factors on stress level. National and global contexts have been proved to influence people's experience of stress. For example, Ragnarsdóttir, Bernburg, and Ólafsdóttir (2013) hypothesized and inspected different outcomes (caused by the global financial crisis) that affect emotional distress and found out that Icelandic people's comparison of past outcomes (to the present) has the most significant impact on their distress. On a similar note, the research by Abu-Ras, Suárez, and Abu-Bader (2018) during the 2016 presidential election in America (where one potential candidate frequently underlined his intention to restrict immigrants from entering the country) discovered that people of certain ethnicities suffer from discrimination stress, which makes them more likely to have higher rate of mental health problems than those who are not discriminated.

In this research, the analysis showed that people residing in Vietnam have less stress compared to those living in Europe during Covid-19. This could be explained by the country's successful containment of the virus compared to others (Quach and Hoang, 2020; Dinh et al., 2020, Huynh, 2020; Ha et al., 2020), which make their citizens feel more secured than those living in nations where the number of infected and death toll is much higher. Even though Vietnam imposes strict quarantine and social-distancing order compared to Western countries, the amazingly lower number of infected cases and death toll in Vietnam implies the undeniable effectiveness of restriction to contain the virus. This country case may have a crucial implication for future treatment and containment of contagious viruses. 
Furthermore, people whose finance is negatively affected by the Covid-19 perceive higher stress than those whose finance is stable. The Covid- 19 has severely disrupted businesses worldwide, causing many people to either lose parts of their regular incomes, or become unemployed. This result suggests that mental health can be severely affected by personal finances. This finding corresponds to the study on families by Wei and Chen (2014) who confirmed that financial stress is significantly related to mental health problems. Sweet et al. (2013) also discovered that high financial debt is associated with higher perceived stress and depression in the US. Similarly, Faresjö (2013) compared the stress level between Greek and Swedish young adults and found out that the Greek had higher perceived stress as a result of living in deteriorating national economic conditions.

Finally, the result showed that people who use social media more frequently reports higher perceived stress. The finding seems contradictory to the study by Bland et al. (2012) who claimed that people used internet social networks as a way to reduce stress. The need to stay connected is perhaps even more imperative during the turbulent time, especially when the majority of respondents lived in quarantined areas at the time this study was conducted. Higher stress from using social media can be explained as even though social networks established through social media is a means of having connectedness and perceived support, such support is superficial, and thus, the more people are connected, the more lonely they can get (Ventriglio and Bhugra, 2017). Besides, people can be stressed out by receiving negative information about the virus daily, especially when social media is used as a channel for the government to communicate with the public concerning health issues (see Coiera, 2013; Neiger et al., 2012, or Mehta and Atreja, 2015). Because in addition to the primary use of social media for keeping in touch with friends and families or for entertainment purpose during the quarantined period, people also rely on this channel for updating and sharing information related to the pandemic. In the case of Vietnam, the government integrated this channel into other initiatives to combat Covid-19, where citizens are regularly updated on the situation and are encouraged to stay connected for timely information. Social media proves to be effective in propaganda; therefore, agenda should be developed to maximize the benefits of this channel (such as connecting people and sharing information) in the time of terror and panic.

\section{Limitations}

The study was not conducted without limitation. First of all, small size of sample may affect the precision of findings. Secondly, the research was conducted at a specific time during the global health crisis, which can only describe the fact at that moment and cannot generate a clear understanding of the impact of situation on stress. In the future, perhaps a larger sample size and a longitudinal study at different times of the pandemic may better explain the effect of situational factors on perceived stress.

\section{Conclusion}

The research is conducted cross-country during a severe global pandemic to investigate the impact of personality and situational factors on perceived stress level. Analysis of data confirms the association between personality traits of negative emotionality and conscientiousness and perceived stress, which is 
consistent with existing literature. The study also shows that people experience moderate stress during the global Covid-19 epidemic and that perceived stress is affected by situational factors including residing country, personal finance, and usage of social media. Future research could inspect stress level through different times of a situation to provide a more comprehensive understanding of how context influences stress.

\section{Declarations}

Authorship: the work is processed by a single author.

Originality and plagiarism: the author has written this entirely original work and appropriately cited or quoted the works of others.

Data access and retention: the author has entire access to raw data and is committed to provide public access to such data.

Funding Statement: this research received no specific grant from any funding agency, commercial or notfor-profit sectors.

Conflict of Interest: the author has no conflict of interest.

Ethical Standards: this work does not involve chemicals, procedures or equipment that have any unusual hazards inherent in their use, or the use of animal or human subjects. All human participants in the survey featured in this work are voluntary.

The authors assert that all procedures contributing to this work comply with the ethical standards of the relevant national and institutional committees on human experimentation.

\section{References}

Abu-Ras, W., Suárez, Z., and Abu-Bader, S. (2018). Muslim Americans' Safety and Well-Being in the Wake of Trump: A Public Health and Social Justice Crisis. American Journal of Orthopsychiatry,88(5), pp. 503515.

Besser, A., and Shackelford, T. K. (2007). Mediation of the effects of the big five personality dimensions on negative mood and confirmed affective expectations by perceived situational stress: A quasi-field study of vacationers. Personality and Individual Differences, 42, pp. 1333-1346.

Bland, Helen W., Melton, Bridget F., Welle, Paul, and Bigham, Lauren. (2012). Stress tolerance: New challenges for millennial college students.(Report). College Student Journal,46(2), pp. 362-375.

Borkoles, E., Kaiseler, M., Evans, A., Ski, C., Thompson, D., and Polman, R. (2018). Type D personality, stress, coping and performance on a novel sport task. PLoS One,13(4), E0196692. 
Coiera, E. (2013). Social networks, social media and social diseases. British Medical Journal, 346, pp. $22-24$.

Costa, P. T., and McCrae, R. R. (1992). Normal personality assessment in clinical practice: The NEO Personality Inventory. Psychological Assessment, 14(1), pp. 5-13.

Saleh, D., Romo, L., and Camart, N. (2017). Is Perceived Stress of French University Students Related to

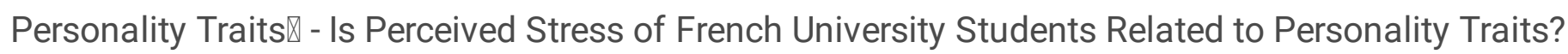
Psychology Research, 7(01), pp. 42-49.

Dinh, L., Dinh, P., Nguyen, Phuong D.M, Nguyen, Duy H.N, and Hoang, T. (2020). Vietnam's response to COVID-19: Prompt and proactive actions. Journal of Travel Medicine,27(3), Journal of travel medicine, 18 May 2020, Vol.27(3).

Ebstrup, J. F., Eplov, L. F., Pisinger, C., and Jørgensen, T. (2011). Association between the five factor personality traits and perceived stress: Is the effect mediated by general self-efficacy? Anxiety, Stress and Coping: An International Journal, 24, pp. 407- 419.

Faresjö, Å., Theodorsson, E., Chatziarzenis, M., Sapouna, V., Claesson, H., Koppner, J., and Faresjö, T. (2013). Higher Perceived Stress but Lower Cortisol Levels Found among Young Greek Adults Living in a Stressful Social Environment in Comparison with Swedish Young Adults. PLoS ONE,8(9), E73828.

Feizi, A., Keshteli, A., Nouri, F., Roohafza, H., and Adibi, P. (2014). A cross-sectional population based study on the association of personality traits with anxiety and psychological stress: Joint modeling of mixed outcomes using shared random effects approach. Journal of Research in Medical Sciences, 19(9), pp. 113.

Fornés-Vives, J., García-Banda, G., Frías-Navarro, D., Hermoso-Rodríguez, E., and Santos-Abaunza, P. (2012). Stress and neuroticism in Spanish nursing students: A two-wave longitudinal study. Research in Nursing and Health,35(6), pp. 589-597.

Guznov, S., Matthews, G., and Warm, J. (2010). Team Member Personality, Performance and Stress in a RoboFlag Synthetic Task Environment. Proceedings of the Human Factors and Ergonomics Society Annual Meeting,54(19), pp. 1679-1683.

Ha, B., Ngoc Quang, L., Mirzoev, T., Tai, N., Thai, P., and Dinh, P. (2020). Combating the COVID-19 Epidemic: Experiences from Vietnam. International Journal of Environmental Research and Public Health,17(9), International journal of environmental research and public health, April 30, 2020, Vol.17(9).

Hojat, M., Gonnella, J. S., Erdmann, J. B., and Vogel, W. H. (2003). Medical students' cognitive appraisal of stressful life events as related to personality, physical well-being, and academic performance: A longitudinal study. Personality and Individual Differences,35, pp. 219-235. 
Huynh, T. (2020). The COVID-19 containment in Vietnam: What are we doing? Journal of Global Health, 10(1), 010338.

Kallio, J., Vildjiounaite, E., Koivusaari, J., Räsänen, P., Similä, H., Kyllönen, V., Muuraiskangas, S.; Ronkainen, J.; Rehu, J.; and Vehmas, K. (2020). Assessment of perceived indoor environmental quality, stress and productivity based on environmental sensor data and personality categorization. Building and Environment,175, Building and Environment, 15 May 2020, Vol.175.

Knight, C.J.; Reade, I.L.; Selzler, A-M; and Rodgers, W.M. (2013). Personal and situational factors influencing coaches' perceptions of stress. Journal of Sports Sciences, 31(10), pp. 1054-1063

Kondratyuk, N., andMorosanova, V. (2014). The relationship between self-regulation, personality traits and job stress. Personality and Individual Differences, 60, S75.

Lebois, L., Hertzog, C., Slavich, G., Barrett, L., and Barsalou, L. (2016). Establishing the situated features associated with perceived stress. Acta Psychologica,169, pp. 119-132.

Lazarus, R. S. (1999). Stress and emotion: A new synthesis. London: Free Association.

Lazarus, R. S., and Folkman, S. (1984). Stress, appraisal and coping. New York: Springer Pub. Co.

Luo, J., Derringer, J., Briley, D., and Roberts, B. (2017). Genetic and Environmental Pathways Underlying Personality Traits and Perceived Stress: Concurrent and Longitudinal Twin Studies. European Journal of Personality, 31(6), pp. 614-629.

Luo, J., and Roberts, B. (2015). Concurrent and longitudinal relations among conscientiousness, stress, and self-perceived physical health. Journal of Research in Personality,59, pp. 93-103.

Mehta, N., Atreja, A. (2015). Online media support networks. International Review of Psychiatry, 27, pp. 118-123.

McCrae, R. R., and Costa, P. T. (1999). A five-factor theory of personality. In L. A. Pervinand O. P. John (Eds.), Handbook of personality (2nd ed., pp. 139-153). New York, NY: The Guilford Press.

Neiger, B. L., Thackeray, R., Van Wagenen, S. A., Hanson, C. L., West, J. H., Barnes, M. D., Fagen, M. C. (2012). Use of social media in health promotion: Purpose, key performance indicators, and evaluation metrics. Health Promotion Practice, 13, pp. 159-164.

Onah, H. (2003). Perceived environmental stress factors and their correlates among pregnant Nigerians. International Journal of Gynecology and Obstetrics, 83(2), pp. 215-218.

Quach, H., and Hoang, N. (2020). COVID-19 in Vietnam: A lesson of pre-preparation. Journal of Clinical Virology, $127,104379$. 
Ragnarsdóttir, B., Bernburg, J., and Ólafsdóttir, S. (2013). The global financial crisis and individual distress: The role of subjective comparisons after the collapse of the Icelandic economy. Sociology,47(4), pp. 755-775.

Şahin, F., andÇetin, F. (2017). The Mediating Role of General Self-Efficacy in the Relationship Between the Big Five Personality Traits and Perceived Stress: A Weekly Assessment Study. Psychological Studies,62(1), pp. 35-46.

Schmidt, L.I., Sieverding, M., Scheiter, F., and Obergfell, J. (2015) Predicting and explaining students' stress with the Demand-Control Model: does neuroticism also matter? Educational Psychology, 35(4), 449-465, DOI: 10.1080/01443410.2013.857010

Sherman, R., Rauthmann, J., Brown, N., Serfass, D., and Jones, A. (2015). The Independent Effects of Personality and Situations on Real-Time Expressions of Behavior and Emotion. Journal of Personality and Social Psychology, 109(5), pp. 872-888.

Shields, G., Toussaint, L., andSlavich, G. (2016). Stress-related changes in personality: A longitudinal study of perceived stress and trait pessimism. Journal of Research in Personality,64, pp. 61-68.

Soto, C., and John, O. (2017). Short and extra-short forms of the Big Five Inventory-2: The BFI-2-S and BFI-2-XS. Journal of Research in Personality,68(C), pp. 69-81.

Sweet, E., Nandi, A., Adam, E., and McDade, T. (2013). The high price of debt: Household financial debt and its impact on mental and physical health. Social Science and Medicine,91, pp. 94-100.

Ventriglio, A., and Bhugra, D. (2017). Social media and social psychiatry. International Journal of Social Psychiatry,63(3), pp. 179-180.

Vollrath, M. (2001). Personality and stress. Scandinavian Journal of Psychology, 42, pp. 335- 347.

Watson, D., and Hubbard, B. (1996), Adaptational style and dispositional structure: coping in the context of the five-factor model. Journal of Personality, 64, pp. 737-774

Wei, H., and Chen, J. (2014). The Relationships Between Family Financial Stress, Mental Health Problems, Child Rearing Practice, and School Involvement Among Taiwanese Parents with School-Aged Children. Journal of Child and Family Studies,23(7), pp. 1145-1154.

Wilson, R., Thompson, R., and Vazire, S. (2017). Are fluctuations in personality states more than fluctuations in affect? Journal of Research in Personality, 69(C), pp. 110-123.

Wordometers (2020). Coronavirus Cases. Retrieved from https://www.worldometers.info/coronavirus/? $14^{\text {th }}$ June, 2020. 
Wrzus, C., and Roberts, B. (2017). Processes of Personality Development in Adulthood: The TESSERA Framework. Personality and Social Psychology Review,21(3), pp. 253-277.

Figures

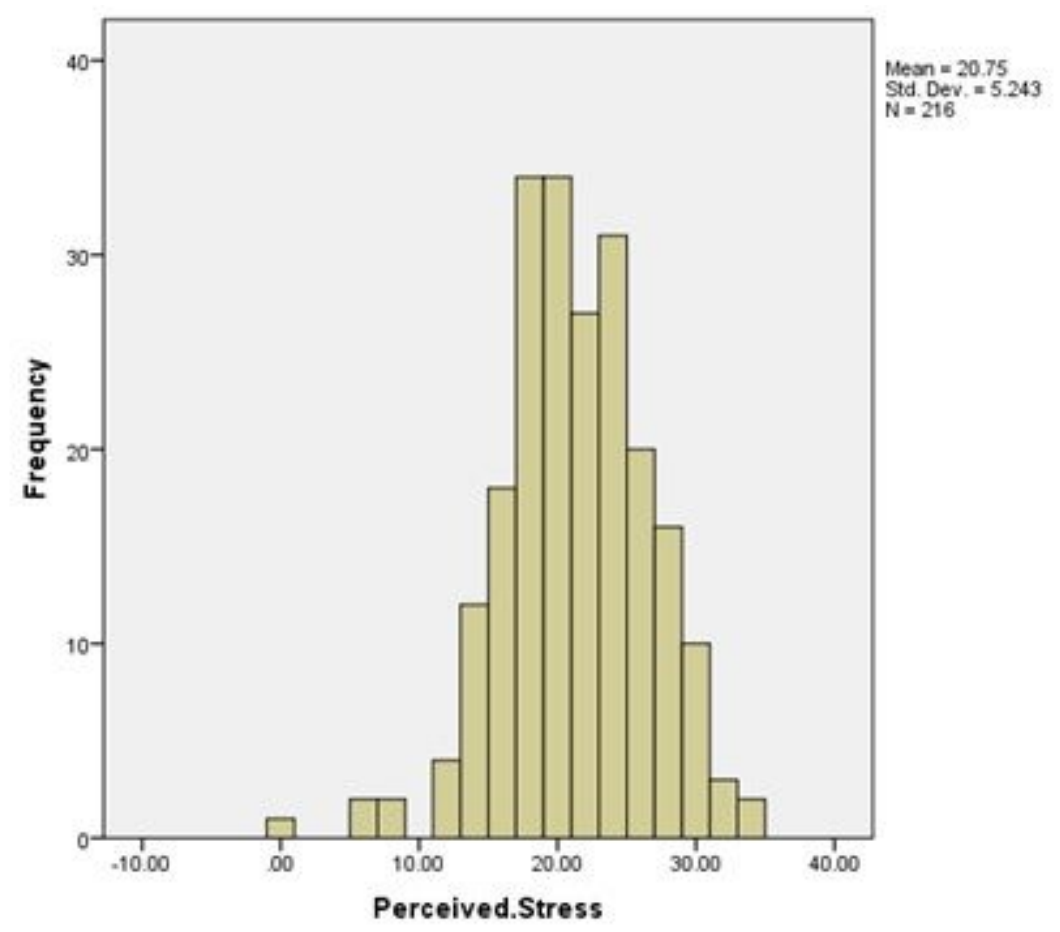

Figure 1

Stress level during Covid-19 pandemic 